Peeters, J.M., Francke, A.L., Friele, R.D., Spreeuwenberg, P.M.M., Graaf, K.C. de, Beek, A.P.A. van.

Development and initial testing of an instrument to establish eating profiles of clients in pursing homes or elderly homes.

Journal of Nutrition for the Elderly: 2008, 27(1-2), 47-64

nivel

\begin{tabular}{|l|l|}
\hline Postprint Version & 1.0 \\
\hline Journal website & $\begin{array}{l}\text { https://www.haworthpress.com/store/ArticleAbstract.asp?sid=4VDT9C1WWD } \\
\text { RQ9GKL7SD0EVAS0J6D358E\&ID=110687 }\end{array}$ \\
\hline Pubmed link & $10.1080 / 01639360802059712$ \\
\hline DOI
\end{tabular}

This is a NIVEL certified Post Print, more info at http://www.nivel.eu

\title{
Development and Initial Testing of an Instrument to Establish Eating Profiles of Clients in Nursing Homes or Elderly Homes
}

José PEETERS IS RESEARCHER AT THE NETHERLANDS INSTITUTE FOR HEALTH SERVICES RESEARCH, THE NIVEL.

ANNEKE FRANCKE IS COORDINATOR OF THE RESEARCH PROGRAMME 'NURSING AND CARE' IN NIVEL.

ROLAND FRIELE IS HEAD RESEARCH DEPARTMENT AND HEAD NIVEL KNOWLEDGE CENTRE.

PETER SPREEUWENBERG IS METHODOLOGIST AT THE NIVEL.

KEES DE GRAAF IS PROFESSOR, DIVISION OF HUMAN NUTRITION AND EPIDEMIOLOGY AT THE WAGENINGEN UNIVERSITY.

SANDRA VAN BEEK IS RESEARCHER AT THE NIVEL.

Address correspondence to: José Peeters PhD, Netherlands Institute for Health Services Research (NIVEL), P.O. Box 1568, 3500 BN Utrecht, The Netherlands, +31302729628 (Email: j.peeters@nivel.nl).

\begin{abstract}
Eating profiles' can be defined as types of clients distinguished by combinations of food preferences, consumption patterns and preferences for ambiance. The purpose of this article is to describe the development and initial testing of an instrument to establish eating profiles of residents of nursing homes or elderly homes. We constructed a 35-item, 4-subscale questionnaire. By this self-administered, usable instrument, five eating profiles derived from clients' perspectives, were distinguished. Insight in eating profiles is important for facility managers to ascertain whether the food, dinner service and ambiance are adequately tailored to the residents' preferences.
\end{abstract}



van.

Development and initial testing of an instrument to establish eating profiles of clients in pursing homes or elderly homes.

Journal of Nutrition for the Elderly: 2008, 27(1-2), 47-64

\section{INTRODUCTION}

Eating and drinking occupy an important place in the existence of many clients of nursing homes and elderly homes, which is a universal phenomenon. Food quality and good meal services are important because they are keys to the quality of life for nursing home residents, contributing significantly to health, well being and satisfaction with care (Mathey, Vanneste, de Graaf, de Groot and van Staveren, 2001; Kayser-Jones, 2000). The quality of food and meal services is an issue about which people are very pronounced (Schultz, Crogan and Evans, 2005). Food quality was the best predictor of patient satisfaction with meals and food service, followed by customisation and attitude by the staffs who deliver menus (Dube, Trudeau and Belanger, 1994).

In studies as shown by Crogan, Evans, Severtsen and Schultz (2004) and Evans, Crogan and Schultz (2005) nursing home residents missed their own homes and the control of their own diets. Food reminded them of their ethnic or cultural identities and elderly missed the dining ambiance to which they were accustomed. Unfortunately the food quality and food service that accommodate the residents' preferences (Evans, Crogan and Schulz, 2003) are not common in nursing homes or elderly homes.

In studies of mealtimes in institutions for elderly people the organisation of meals was found to be task-oriented rather than resident-oriented, in ways which failed to meet the need of residents (Sidenvall, 1999). In nursing homes and elderly homes, meals are often not served in a cosy setting: meals may be individually served on trays, in a non-stimulating social environment. Such meals provide task oriented care rather than resident oriented care (Sidenvall, 1999; Nijs, de Graaf, Kok and Van Staveren, 2006). Changing the meal ambiance in a more resident tailored than task/organisational oriented way, may stimulate residents' perceived satisfaction and indirectly stimulate general well-being of nursing home residents (Nijs, de Graaf, Kok and Van Staveren 2006). Organisations who aim to offer resident tailored food services have to know the 'eating profiles' of their residents. Eating profiles can be defined as types of clients distinguished by combinations of food preferences, consumption patterns and preferences for ambiance.

In existing literature no attention is paid to eating profiles of elderly clients. But some qualitative studies were performed on residents' satisfaction about nursing home food and food service, food preferences (Pierce. Hodges, Merz and Olivey, 1988; Holt, Norstrom and Kohrs 1987; 1998) the meaning of food related to the residents' family background (Crogan, Evans, Severtsen and Schulz, 2004) and what mealtimes mean for the elderly (Evans, Crogan and Shultz, 2005). Other studies found out that strategies selected for nutrition in nursing homes must account for the residents' personal food and food service experiences (Evans, Crogan and Schultz, 2003).

There are also a few reports of studies focussing on the need for a fine ambiance of food consumption of nursing home elderly residents (Mathey, 2001; Nijs, de Graaf, Kok and van Staveren, 2006). So there are studies that have been published about food service satisfaction, food quality and quality of life in the long-term care facilities.

Also some studies on the development of instruments are published, e.g. a validated questionnaire examining food service satisfaction and quality of life in long-term care facilities: the FoodEx LTC (Crogan, Evans and Velasquez, 2004; Evans, Crogan and Schulz, 2005). This questionnaire measures residents' expectations, perceived control of food and food service procedures and organizational aspects. We also found instruments to measure appetite and weight loss: Appetite Hunger and Sensory Perception questionnaire (AHSP; Mathey, 2001), Council on Nutrition Appetite Questionnaire (CNAQ; Wilson, Thomas, Rubenstein, Chibnall, Andersone, Baxi, Diebold and Morley, 2005) an appetite assessment tool that predicts weight loss in community-dwelling adults and long-term care residents, Mini Nutritional Assessment (MNA; Vellas, Garvey \& Gouigoz., 1999). Food and Fluid 

van.

Development and initial testing of an instrument to establish eating profiles of clients in pursing homes or elderly homes.

Journal of Nutrition for the Elderly: 2008, 27(1-2), 47-64

Estimation Diagram (FFED; Andrews and Castellanos, 2003) and the Nutritional Risk

Screening Tool (NRST; Green and Watson, 2006).

To conclude, previous studies are focused on food satisfaction and food preferences of the elderly in general. However, little is known about the existence and the variety of 'eating profiles' of clients in nursing homes and elderly homes, taking into account food preferences, consumption patterns and preferences for ambiance. For resident-oriented care, it is important that facility managers in nursing homes or elderly homes have insight into the eating profiles of their clients and into the differences between eating profiles from the residents' perspective. There was no instrument available to distinguish eating profiles, so we have developed such an instrument. The purpose of this article is to describe the development and the initial testing of an instrument - a questionnaire - meant to distinguish eating profiles, based on the clients' perspectives.

\section{METHODS}

This study was conducted in two phases: (1) a development phase (literature study, focus group discussions, qualitative interviews and pre-testing) and (2) a quantitative, testing phase.

\section{Methods phase 1: development of the instrument}

The first stage included the identification of the dimensions that may be important to distinguish eating profiles, by performing a literature study and group and individual interviews.

\section{Literature search}

A literature search was performed in the international databases Pubmed, Psychinfo and CINAHL. First we searched for the terms 'appetite', 'meal', 'nursing homes', 'residential care', 'food' and 'ambiance'. Then we combined the hits with more specific terms: 'preference', 'satisfaction', 'attitude', 'eating behavior' and 'old age'. The aim of the literature search was to identify issues that are important to take into account in developing an instrument to establish eating profiles.

\section{Focus Group Discussions}

To further explore important issues in the residents' preferences regarding food consumption, consumption patterns and ambiance, we performed focus group discussions with residents of nursing homes and elderly homes. In this phase sixteen nursing homes and elderly homes participated, from two different regions in the west (urban area) and in the east of the Netherlands (rural area). We spread the total number of clients as much as possible across the organizations and regions to differentiate between the two regions.

Two focus groups of clients (13 clients in total) were set up. In addition, two focus groups of a total of 11 relatives (partner, son or daughter) of residents with dementia problems were set up. The residents and relatives were selected by the managers of the participating nursing homes and elderly homes. They had to make sure there was a proportional division between the groups of our study: residents with somatic problems, residents with psycho-geriatric problems, rehabilitation residents and outpatient clients who did make use of the meal services. The instruction to the managers was to differentiate as much as possible between age, gender and social background. The clients and relatives involved all gave informed consent.

The sessions were videotaped and transcribed. We started the focus group discussions with the question "What is important to you about a good meal?" The relatives were asked to themselves into the position of the resident. We also asked the clients and the relatives to describe their favorite meal, to relate in detail their preferences for ambiance, the 

van.

Development and initial testing of an instrument to establish eating profiles of clients in pursing homes or elderly homes.

Journal of Nutrition for the Elderly: 2008, 27(1-2), 47-64

accompaniments and at what time they like to eat. The focus group discussions were very informative (also see section 'Findings').

\section{Individual interviews}

We also used in-depth interviews to generate more specific aspects of food and ambiance that are important to elderly. The topics we concentrated on were the same as in the focus group discussions. We interviewed seven additional clients with various backgrounds (social and ethnic). The clients were selected by the managers of the nursing homes and elderly homes, on the same selection criteria as the selection for participation to the focus groups took place. We also interviewed two relatives of residents with dementia problems. The interviewing took more than one hour and was very animated, which illustrates that food and drinks are important issues for the clients. The interviews were audio taped and transcribed word for word. For results, see section 'Findings'.

\section{Data analysis of group discussions and interviews}

We coded each focus group discussion and each individual interview by hand, according to the themes derived from the literature search and as cited by the participants during the focus group discussions and individual interviews. The codes were applied to subsequent interviews, refined and grouped into draft dimensions. (For draft dimensions, see section 'Findings'.) This preliminary analysis was presented to colleague researchers and professionals of the participating nursing homes and elderly homes, to find out to what extent they recognized the dimensions and to obtain suggestions to complete the analysis.

\section{Methods phase 2: instrument testing in 309 clients}

\section{First draft instrument}

The fist draft was based on the insights of the previous literature study, group discussions and individual interviews. The draft questionnaire contained 49 items about clients' preferences, divided into two sections. The first section contained 35 items to measure food preferences and consumption patterns. The second section, on ambiance of food consumption, is contained in 14 items. The reliability of the questionnaire was measured using tests of internal consistency (Cronbach's alpha).

\section{Sample and response}

In the quantitative phase of our study we further tested the instrument among clients in nursing homes and elderly homes. Residents with dementia problems were not able to complete the questionnaire by themselves. Instead, we asked a relative to fill in the questionnaire from the residents' perspective. In principle all clients of the nursing homes and elderly homes, except the residents with psycho-geriatric problems, were included in the sample. Residents in the terminal phase, defined as those who have a life expectancy of less than six weeks, were also excluded.

The instruction was given to staff members to select every fifth client on the clients' list to be involved in the study. The sample consisted of four groups of residents of nursing homes and elderly homes, both long-stay and short-stay: residents with (serious) somatic problems, psycho-geriatric residents, rehabilitation residents and clients of assisted living facilities. We made this division beforehand.

A total of 309 questionnaires were completed. The participating nursing homes and elderly homes sent the questionnaire to 728 clients in total, which means the response rate is $42 \%$. Table 1 lists the sample characteristics of the participating clients.

\section{[TABLE 1$]$}


Peeters, J.M., Francke, A.L., Friele, R.D., Spreeuwenberg, P.M.M., Graaf, K.C. de, Beek, A.P.A. van.

Development and initial testing of an instrument to establish eating profiles of clients in pursing homes or elderly homes.

Journal of Nutrition for the Elderly: 2008, 27(1-2), 47-64

Table 1 makes clear that most of the residents that participated in our research are widowed female residents with a low education in the two oldest age groups. In spite of the attempt to sufficiently represent the rehabilitation residents in our study, they are less well represented in comparison with other resident types.

\section{Data analyses}

Data analyses included item and inter-item analyses (non-response, skewness, correlations), explorative factor analyses (Principal Component Analysis with varimax rotation and Kaiser normalisation) and reliability analysis. Prior to factor analysis, the Kaiser-Meyer-Olkin (KMO) Measure of Sampling Adequacy was applied. We found a KMO of .77 for the section about food preferences and consumption patterns, and a KMO of .66 for the ambiance section, which means that factor analyses can be used. We chose Varimax rotation because not much is known about this subject.

In addition, multi level analyses were performed to distinguish eating profiles. We used SPSS for Windows, version 11.5 and ML-Win 2.0 (for the multi-level analysis).

\section{FINDINGS}

\section{Findings phase 1: development of the instrument}

\section{Findings of the literature study}

Clients' perspective on the quality of food, the presentation, tastiness and serving of the food, the choice about when, where or what to eat in a novel way, the favorite food, and criticisms on the food itself are important themes derived from the literature (Pierce, Hodges, Merz \& Olivey, 1998; Evans, Crogan \& Schultz, 2003; Crogan, Evans \& Schultz, 2004) and which have been formulated into items in the questionnaire.

\section{Findings of the focus group discussions and individual interviews}

The animated focus group discussion and the individual interviews showed that the taste and presentation of the meals were further important aspects of eating and drinking. Choices regarding meal service and the choice of whom to eat with were also issues clients often mentioned.

The analyses of this qualitative part of the study resulted in multiple draft dimensions, for example: 'Grateful attitude', 'Critical attitude' and 'Socially or individually oriented'. We also distinguished two domains: the first involves food preferences and consumption patterns and the second section concerns ambiance. We used these domains to compose the structure of the draft questionnaire.

\section{Pre-testing the first draft}

This resulted in 49 items to be included in the first draft of the questionnaire for clients in nursing homes or elderly homes. This draft was pre-tested for usability and clarity in a sample of five elderly. It took less than 30 minutes on average to fill in the questionnaire, which was found to be acceptable. The revised draft of the questionnaire was used in the next phase, in which the instrument was further tested.

\section{Face validity and content validity}

The draft instrument's face validity and content validity was discussed and established in the steering group. Members of the steering group were two food experts, three managers/staff members of nursing homes or elderly homes and four scientists with relevant expertise. 

van.

Development and initial testing of an instrument to establish eating profiles of clients in pursing homes or elderly homes.

Journal of Nutrition for the Elderly: 2008, 27(1-2), 47-64

Findings phase 2: instrument testing in 309 clients

\section{Item non-response and usability}

The residents' preferences regarding food consumption, food patterns and ambiance were translated into items. The low item non-response (between 3.5\% and 10.6\%) means that the items are relevant to the clients.

Filling in the questionnaire did not seem a problem to almost all of the 309 clients participating in this phase of the study. The items on the questionnaire appeared to be understandable for elderly and it did not take too much time to complete the questionnaire. Nevertheless, from a practical point of view, a scale with 49 items is still too long and needs some reduction.

\section{Section 1: Outcomes factor analysis and reliability}

For questionnaire section one, concerning the food preferences and consumption patterns, a forced five-factor Principal Component Analysis solution fitted the data best. The underlying structure, the factor loadings and internal consistencies are presented in Table 2. We only represent the items with the highest factor loadings and the items which mainly contribute to the internal consistency of the scale. The reliability of all the scales is sufficient (Cronbach's alpha between .63 and .72, see Table 2).

Internal consistency reliability (Cronbach's alpha) estimates .76 for section one of the first draft of the questionnaire (49 items) and .77 for section one in the definite questionnaire with 35 items (see Appendix 1), leading us to conclude that this questionnaire section appears to be internal consistent.

\section{[TABLE 2]}

\section{Section 2 Ambiance}

For assessing the internal consistency of section two of the draft questionnaire, the 14 items about ambiance, we also used Cronbach's alpha. The data made it possible to construct a reliable scale of the items referring to an important aspect of the clients' perspective to ambiance: social versus individual orientation. The internal consistency of the scale and the importance of the items (alpha if item is deleted) are shown in Table 3.

\section{[TABLE 3]}

Accordingly, the statistical analyses produced six dimensions that are important in describing the residents' preferences with regard to eating and drinking. These dimensions are based on our interpretation of the factor analyses (Table 2) and the Cronbach's alpha (Table 3).

Based on the process of scale optimization, we were able to reduce the list to 35 items in the definitive draft of the questionnaire: 30 items are necessary to allocate eating profiles (see Appendix 1). Five items about the quality and the presentation of the food are also part of the definitive questionnaire because more than $90 \%$ of the clients considered these items to be very important.

\section{Distinguishing eating profiles}

The next step in the analyses was to explore distinctive eating profiles. To find out if this was possible, we had to cluster the participants in groups, based on Item Response Theory (Bezruczko, 2005).

For the construction of the scale scores we used a multilevel Rasch model (a scale score represents a dimension of eating profiles). One of the advantages of this model is that cases with missing data on some items can still be used to construct a scale score. Together 

van.

Development and initial testing of an instrument to establish eating profiles of clients in pursing homes or elderly homes.

Journal of Nutrition for the Elderly: 2008, 27(1-2), 47-64

with this scale score (see Table 2 and Table 3 ) we get a standard error, which is used to construct a comparison interval. By comparing these intervals between individual respondents we created three groups per scale/dimension: (1) those who, relatively score above average on the dimension, (2) those who score below average and (3) those who are in the middle. This grouping on the dimensions is used in the next step to create and describe eating profiles. First we looked at the scale means and variance to see if they vary sufficiently to be useful in the creation of the eating profiles.

We noticed that almost everyone believes that the 'Presentation and variation' of food and drinking is important. This also applies to 'Liking snacks'. Because of the lack of variation in the answers between residents' on both these scales, we decided not to involve the dimensions 'Presentation and variation' and 'Liking snacks' in further analyses.

In the following step in exploring eating profiles we made a combination of the two dimensions 'Adventurous' with the opposite 'Traditional' as well as the dimension 'Critical' with the opposite 'Grateful'. For the distinction in eating profiles, we were looking for the combinations to which most of the clients belonged.

We used the multilevel Rasch model, as mentioned before, and finally detected five distinctive 'eating profiles' ( $\mathrm{N}=295)$ :

1. the easy eater $(n=58$ or $20 \%)$

2. the adventurous eater $(n=45$ or $15 \%)$

3. the critical eater ( $n=38$ or $13 \%)$

4. the traditional eater $(\mathrm{n}=38$ or $13 \%)$

5. the grateful eater ( $\mathrm{n}=36$ or $12 \%)$

6. the adventurous and critical eater $(n=14$ or $5 \%)$

7. the traditional and grateful eater ( $n=10$ or $3 \%$ )

It was possible to classify almost all the clients to a particular eating profile; only for a few residents we were not able to classify them into one of the eating profiles, since they have characteristics of two eating profiles (see 6 en 7). Appendix 2 displays the main characteristics of each eating profile.

\section{STRENGHT AND LIMITATIONS OF THE STUDY}

This study focuses on the residents' preferences for food, consumption patterns and residents' preferences for ambiance. The strength of the study is that we developed and tested a new, usable questionnaire, to measure eating profiles of clients in nursing homes or elderly homes. This 4 subscale questionnaire with 35 items is meant to distinguish eating profiles. The instrument enables nursing homes or elderly homes to classify their clients in eating profiles - distinguished on the basis of combinations of food preferences, consumption patterns and preferences for ambiance - and to adapt the food service for the needs of their clients.

The internal consistency of the instrument is sufficient, except for the scale 'social orientation': social orientation is very complex and elderly in nursing homes and elderly homes are very heterogeneous. Besides the questionnaire has to be practical and short, so it was no option to maintain all the items of the draft questionnaire.

The instrument, as described in this article, used items that are relevant to clients of nursing homes and elderly homes, because the items are emerged from focus group discussions and in-depth interviews with the clients. In the developmental phase we explored differences between clients and between nursing homes and elderly homes about when, what and with whom they like to eat and about the ambiance. The existence of these differences were tested and confirmed, and resulted in different, distinctive eating profiles.

A limitation is that the questionnaire is cultural specific, because the questionnaire is conducted with the help of clients of Dutch nursing homes or elderly homes. Ninety percent of the residents were born in the Netherlands, seven percent were born in another European country and three percent came from Indonesian, Surinam and the Antilles. Traditional food 

van.

Development and initial testing of an instrument to establish eating profiles of clients in pursing homes or elderly homes.

Journal of Nutrition for the Elderly: 2008, 27(1-2), 47-64

has another meaning for residents who have always lived in Holland than for elderly who are used to eat rice dishes. Some items may be typically Dutch and should be translated and adjusted at the customs of the country.

The instrument is however tested in different groups of elderly in the Netherlands: residents with serious somatic problems, psycho geriatric residents, rehabilitation residents and outpatient clients. Also important is that the results showed differences between the nursing homes or elderly homes in the west (urban area with cultural differences) and the east (countryside, native country is Holland) of the Netherlands. We found out that, according to our expectations, the residents in the east are more traditional about eating and drinking and residents from nursing homes and elderly homes in the west are more adventurous. This means that elderly homes and nursing home differ in the mix of the eating profiles and that the instrument is sensitive with regard to the different elderly homes and nursing homes.

A weakness in our study is that family members filled in the questionnaire as proxy for clients with dementia problems. However, it is very difficult to project one's mind; also the preferences in food may change in the case of clients with dementia problems, due to the illness. That is why we argue for supplementary observation of the eating behaviour of clients with dementia problem by nurses.

\section{PRACTICAL IMPLICATIONS FOR FOOD SERVICE}

The questionnaire, as described in this article, is an instrument that can be used by nursing homes and elderly homes to detect residents' eating profiles to improve the quality of meals and meal service from the clients' perspective. Lack of attention to food that is adapted to the residents' needs is a risk for undernutrition and loss of weight, which is negatively influencing the health ant the quality of life of clients of nursing homes and elderly homes (Amarantos, Martinez \& Dwyer, 2001).

Therefore it is recommended that nursing homes and elderly homes adjust their meal services to a more resident friendly system based on the residents' eating profiles. The instrument can be useful to the nursing homes and the elderly homes, for example regarding the menu planning.

Of course it is important that residents in nursing homes or elderly homes really enjoy their food and that they may complain when they are unhappy. An instrument such as the FoodEx-LTC may be a useful instrument for the staff to elicit this information. But in our opinion it is not enough to know if residents are satisfied with the food or not. More important is that the dinner service and the ambiance are connected to clients' eating profiles. The challenge for nursing homes and elderly homes is to acknowledge residents' eating profiles through client oriented, rather than organisational oriented meal procedures.

Exploring eating profiles can provide insights to improve meal services, adapted to the type eating profiles. Therefore, it is important for managers and staff to know which mix of eating profiles their organisation has. An organisation should get a representative view of the eating profiles of their clients, so it is important to aim for a very high response rate. Only then the staff of the nursing home is able to check the conditions for a suitable dinner service and ambiance, and to know for sure that the nursing home or home for the elderly is able to fulfil their clients' wishes concerning eating and drinking, in their course to a demand driven organisation.

\section{SUGGESTIONS FOR FURTHER RESEARCH}

The items of the questionnaire (presented in Appendix 1) for clients in nursing homes or elderly homes are a literal translation of the Dutch version of the questionnaire. For international use of the instrument, researchers should further test the psychometric features of the English languaged version of the instrument. 
Peeters, J.M., Francke, A.L., Friele, R.D., Spreeuwenberg, P.M.M., Graaf, K.C. de, Beek, A.P.A. van.

Development and initial testing of an instrument to establish eating profiles of clients in pursing homes or elderly homes.

Journal of Nutrition for the Elderly: 2008, 27(1-2), 47-64

Follow-up research will also have to clarify whether the prevalences of eating profiles assessed in this study, can be generalized towards the total population of elderly people living in nursing homes and elderly homes in the Netherlands. The percentages of eating profiles are the results from the sample of our study $(\mathrm{N}=309)$ in two regions (west and eastern part of the Netherlands). This means that when the number of clients and organisations involved would be larger, the percentages as presented, may change. Until now a few more Dutch nursing homes and elderly homes filled in the questionnaire, and the managers of these organisations are very enthusiastic about the results and the implications.

It is also of great importance to measure the residents' well being and quality of life and to find out whether the changes in food presentation and ambiance after being assessed the eating profiles, indeed improved the well being or a higher quality of life. It would be worthwhile to investigate this relationship in further research.

\section{ACKNOWLEDGMENTS}

This research was financially supported by Albron Carewell.

\section{REFERENCES}

Andrews, Y.N. \& Castellanos, V.H. (2003). Development of a method of estimation of flood and fluid intakes by nursing assistants in long-term care facilities: a pilot study 2003 , Journal of American Dietetic Association, July 107(7):873-7.

Amarantos, E., Martinez, A. \& Dwyer, J. (2001). Nutrition and quality of life in other adults. Journal of Gerontological A Biological Sciences and Medical Science, 56(Spec No 2 2):5464.

Bezruczko, N. (2005). Rasch Measurement in health sciences, JAM press, Minnesota: Maple Grove.

Vellas, B., Garvey, J. \& Gouigoz, Y. (1999). Mini Nutritional Assessment (MNA): Research and Practice in the Elderly. Nestle Nutrition Workshop Series Clinical \& Performance Programme, S Kargar AG, Basel: Switzerland.

Crogan, N.L, Evans, B.C., Severtsen, B. \& Schultz, J.A. (2004). Improving nursing home food service: uncovering the meaning of food through residents' stories. Journal of Gerontological Nursing, 30(2):29-36.

Crogan, N.L., Evans, B.C. \& Velasquez, D. (2004). Measuring nursing home resident satisfaction with food and food services: initial testing of the FoodEx-LTC. Journal of Gerontology: Medical Sciences, 59A(4):370-377.

Dube, L., Trudeau, E., \& Belanger, M. (1994). Determining the complexity of patient satisfaction with foodservices, Journal of the American Dietetic Association, 94(4), 394401.

Evans, B.C., Crogan, N.L. \& Schultz, J.A. (2003). Quality dining in the nursing home: the residents' perspective. Journal of Nutrition for the Elderly, 22(3):1-17.

Evans, B.C. \& Crogan, N.L. (2005) Using the FoodEx-LTC to assess institutional food service practices through nursing home residents' perspectives on nutrition care. Journal of Gerontology: Medical Sciences, 60A(1):125-128.

Evans, B.C., Crogan, N.L. \& Schultz, J.A. (2005) The meaning of mealtimes: connection of the social world of the nursing home, Journal of Gerontological Nursing, 31(2):11-17.

Green, S.M. \& Watson, R. (2006). Nutritional Screening and assessment tools for older adults: literature review. Journal of Advanced Nursing, May 54 (4):477-90.

Holt, V., Nordstrom, J. \& Kohrs, M.B. (1987). Food Preferences of older adults. Journal of Nutrition for the Elderly, 6 (3): 47-56.

Holt, V., Nordstrom, J., \& Kohrs, M.B. (1988). Changes in Food Preferences on the Elderly over a Ten Year Period. Journal of Nutrition for the Elderly, 7(4):83-102.

Kayser-Jones J. (1996). Mealtimes in nursing homes: the importance of individualized care. Journal of Gerontological Nursing, ;22(3):26-31. 
Peeters, J.M., Francke, A.L., Friele, R.D., Spreeuwenberg, P.M.M., Graaf, K.C. de, Beek, A.P.A. van.

Development and initial testing of an instrument to establish eating profiles of clients in pursing homes or elderly homes.

Journal of Nutrition for the Elderly: 2008, 27(1-2), 47-64

Mathey, M.F., Vanneste, V.G., de Graaf, C., de Groot, L.C. \& van Staveren W.A. (2001).

Health effect of improved meal ambiance in a Dutch nursing home: a 1-year intervention study. Preventive Medicine, 32:416-423..

Mathey, M.F. (2001). Assessing appetite in Dutch elderly with the Appetite, Hunger and Sensory Perception (AHSP) questionnaire, Journal of Nutrition and Health Aging, 5:22-8.

Nijs, K.A.N.D., de Graaf, C., Kok, F.J. \& Van Staveren, W.A. (2006). Effect of family style mealtimes on quality of life, physical performance and body weight of nursing home residents: cluster randomised controlled trial. British Medical Journal, 332:1180-1184.

Pierce, R.P., Hodges, P.A.M., Merz, B. \& Olivey, A. (1998). Food Preferences and Perceptions of Institutionalized Elderly: a Case Report , Journal of Nutrition for the Elderly, 7(1):35-42.

Schultz, J.A., Crogan, N.L. \& Evans, B.C. Organizational issues related to satisfaction with food and food service in the nursing home from the residents' perspective. Journal of Nutrition for the Elderly, 24(4):39-55.

Sidenvall, B. (1999). Meal procedures in institutions for elderly people: A theoretical interpretation. Journal of Advanced Nursing, 30(2), 319-328.

Wilson, M.G.G., Thomas, D.R., Rubenstein, L.Z., Chibnall, J.T., Andersone, S., Baxi, A., Diebold, M.R. \& Morley, J.E. (2005). Appetite assessment: simple appetite questionnaire predicts weight loss in community-dwelling adults and nursing home residents, American Journal of Clinical Nutrition, 82:1074-81.

\section{TABLES AND ANNEXES}

TABLE 1. Characteristics of the Sample of Participants $(\mathrm{N}=309)$

\begin{tabular}{lc}
\hline Characteristic N (\%) & \\
\hline Age & $\mathrm{N}=305$ \\
Young (under 65) & $16(5.2 \%)$ \\
Young old (65-74) & $41(13.5 \%)$ \\
Old (75-84) & $117(38.0 \%)$ \\
Old old (85+) & $131(43.3 \%)$ \\
Gender & $\mathrm{N}=306$ \\
Male & $86(27.9 \%)$ \\
Female & $221(72.1 \%)$ \\
Marital status & $\mathrm{N}=305$ \\
Never married & $31(10.2 \%)$ \\
Married & $61(19.8 \%)$ \\
Widowed & $201(66.0 \%)$ \\
Divorced & $12(4.0 \%)$ \\
Education & $\mathrm{N}=295$ \\
Low & $189(64.1 \%)$ \\
Middle & $87(29.4 \%)$ \\
High & $19(6.5 \%)$ \\
Group & $\mathrm{N}=309$ \\
Somatic problems & $91(29.4 \%)$ \\
Psycho geriatric problems & $90(29.1 \%)$ \\
Rehabilitation & $48(15.5 \%)$ \\
Assisted living facilities & $80(25.9 \%)$ \\
\hline
\end{tabular}

Note: For age, the mean was 81.5 ; S.D. was 10.03 and range was 27-99.

*Family members of clients with psychogeriatric problems. 
Peeters, J.M., Francke, A.L., Friele, R.D., Spreeuwenberg, P.M.M., Graaf, K.C. de, Beek, A.P.A. van.

Development and initial testing of an instrument to establish eating profiles of clients in pursing homes or elderly homes.

Journal of Nutrition for the Elderly: 2008, 27(1-2), 47-64

Table 2. Items, Dimensions, Factor Loadings and Cronbach's $\alpha$ of Section 1 on Food Preferences and Consumption Patterns $(\mathrm{N}=309)$

\begin{tabular}{|c|c|c|c|c|c|}
\hline Items & Factor 1 & Factor 2 & Factor 3 & Factor 4 & Factor 5 \\
\hline \multicolumn{6}{|c|}{ Dimension 'Presentation and variation' (5 items) } \\
\hline Food has to look appetizing & .79 & & & & \\
\hline Food has to smell good & .77 & & & & \\
\hline $\begin{array}{l}\text { Variation in eating and drinking is } \\
\text { important }\end{array}$ & .54 & & & & \\
\hline Food has to look colorful & .57 & & & & \\
\hline Variety in sandwich filling is important & .51 & & & & \\
\hline \multicolumn{6}{|l|}{ Dimension 'Focused on eating' (6 items) } \\
\hline Dinner is the highlight of the day & & .81 & & & \\
\hline 'Food is a feast' & & .74 & & & \\
\hline Being a big eater & & .56 & & & \\
\hline $\begin{array}{l}\text { Meat is the most important element of } \\
\text { dinner }\end{array}$ & & .53 & & & \\
\hline $\begin{array}{l}\text { Eating and drinking are very important } \\
\text { to me }\end{array}$ & & .52 & & & \\
\hline $\begin{array}{l}\text { Having dinner determines my program } \\
\text { for the day }\end{array}$ & & .51 & & & \\
\hline \multicolumn{6}{|l|}{ Dimension 'Adventurous' (3 items) } \\
\hline I like foreign dishes & & & .80 & & \\
\hline I like to eat unfamiliar dishes & & & .72 & & \\
\hline I like rice dishes & & & .63 & & \\
\hline \multicolumn{6}{|l|}{ Dimension 'Critical' (6 items) } \\
\hline I am critical about eating and drinking & & & & .74 & \\
\hline I am choosey about eating and drinking & & & & .64 & \\
\hline I sometimes complain about the food & & & & .63 & \\
\hline I have a delicate taste & & & & .62 & \\
\hline I like to eat the way I am used to & & & & .51 & \\
\hline I like luxurious dishes & & & & .30 & \\
\hline \multicolumn{6}{|l|}{ Dimension 'Snacks' (3 items) } \\
\hline I like snacks & & & & & .78 \\
\hline I like savory snacks & & & & & .72 \\
\hline I like pastry & & & & & .61 \\
\hline Cronbach's $\alpha$ & 67 & .70 & .72 & .69 & .63 \\
\hline
\end{tabular}

TABLE 3. Items, Cronbach's $\alpha$, and Alpha if Item Deleted, of the Dimension Social Orientation $(\mathrm{N}=309)$

\begin{tabular}{lc}
\hline Social Orientation & Alpha if item deleted \\
\hline A well laid table is important & .56 \\
I like to eat in the company of other residents & .63 \\
I like to chat during dinner & .63 \\
A homely atmosphere is important & .58 \\
A friendly meal service is important & .65 \\
It is important to start the meal collectively & .60 \\
Having dinner is sociable & .63 \\
Cronbach's $\alpha$ & .66 \\
\hline
\end{tabular}


Peeters, J.M., Francke, A.L., Friele, R.D., Spreeuwenberg, P.M.M., Graaf, K.C. de, Beek, A.P.A. van.

Development and initial testing of an instrument to establish eating profiles of clients in pursing homes or elderly homes.

Journal of Nutrition for the Elderly: 2008, 27(1-2), 47-64

nivel

APPENDIX 1. Questionnaire on Eating Profiles (Literal, not Tested Translation of the Dutch Version)

Item

Absolutely Mainly Not really Not at all

1. I am critical about eating and drinking.

2. Dinner is the highlight of the day to me.

3. Eating and drinking are very important to me.

4. I like to eat the way I am used to.

5. I love snacks.

6. I like savory snacks.

7. I like to eat unfamiliar dishes.

8. I am choosey about eating and drinking.

9. Having dinner determines my program for the day.

10. Food is a feast.

11. I sometimes complain about the food.

12. I love pastry.

13. I have a delicate taste.

14. I love rice dishes.

15. Meat is the most important element of dinner.

16. Variation in eating and drinking is important.

17. Food has to look appetizing.

18. Food has to be colorful.

19. Food has to smell good.

20. I love luxurious dishes.

21. Variety in sandwich filling is important to me.

22. I like foreign dishes.

23. The food has to be well done.

24. I love flavored food.

25. I am an easy dinner guest.

28. A well-laid table is important to me.

29. I like to eat in the company of others.

30. I love to chat during dinner.

31. A homely atmosphere is important to me.

32. A friendly service is important to me.

33. It is important to me to start the meal collectively.

34. Having dinner is sociable.

35. I prefer to eat three times a day. 
Peeters, J.M., Francke, A.L., Friele, R.D., Spreeuwenberg, P.M.M., Graaf, K.C. de, Beek, A.P.A. van.

Development and initial testing of an instrument to establish eating profiles of clients in pursing homes or elderly homes.

Journal of Nutrition for the Elderly: 2008, 27(1-2), 47-64

APPENDIX 2. MAIN CHARACTERISTICS OF

THE EATING PROFILES

The easy eater

- Does not really like foreign dishes

- Does not really like to eat unfamiliar dishes

- Does not really like rice dishes

- Is not really critical about eating and drinking

- Is not really choosey about eating and drinking

- Does not really complain about the food

- Does not really have s a delicate taste

- Does not really like to eat the way he/she is used to

- Does not really like luxurious dishes

The adventurous eater

- Likes foreign dishes

- Likes to eat unfamiliar dishes

- Likes rice dishes

The critical eater

- Is critical about eating and drinking

- Is choosey about eating and drinking

- Sometimes complains about the food

- Has a delicate taste

- Likes luxurious dishes

The traditional eater

- Does not like foreign dishes

- Does not like to eat unfamiliar dishes

- Does not like rice dishes

The grateful eater

- Is not critical about eating and drinking

- Is not choosey about eating and drinking

- Does not complain about the food

- Does not have a delicate taste

- Does not like luxurious dishes 